\title{
Hailey-hailey disease presenting at an unusual site
}

\section{Nabeel K. Al Hamzawi}

\author{
Department of Dermatology, Diwaniyah teaching hospital, Diwaniyah, Iraq
}

Corresponding author: Dr. Nabeel K. Al Hamzawi, E-mail: alhamzawi_n@yahoo.com

Sir,

A 37-year-old patient presented with painful crusted skin lesions on the scalp for one year. The condition started as small blisters that ruptured spontaneously to form crusted erosions. He had similar lesions in the axillae and groin from two years past, which later developed into warty plaques. There was no family history of the same condition nor was relevant medical history. The patient experienced more exacerbation in the summer months as he worked as a taxi driver and spent most of the day outdoors. Dermatological examination showed four crusted lesions on the scalp, a big one of $4 \times 5 \mathrm{~cm}$ near to the vertex, and the remaining three about $1 \times 2 \mathrm{~cm}$ each located around it (Fig. 1 a). Moreover, there was a warty plaque measuring $2 \times 3 \mathrm{~cm}$ in the right axilla (Fig. 1 b). Oral mucosa and nails revealed no abnormality. Swabs for bacteriological and fungal analysis showed negative results. Blood routine investigations, chemistry tests, and CXR all were normal. Histopathological study revealed intraepidermal cleft and bullous formation containing aggregates of acantholytic cells that arranged in a "dilapidated brick wall appearance" (Fig. 2). Direct immunofluorescence test was negative for immune reactants. A correlation between the clinical picture and the histopathology findings confirmed the diagnosis of Hailey-Hailey disease. The patient was prescribed systemic antibiotics flucloxacillin 500mg 8 hourly, oral Acitretin $25 \mathrm{mg} /$ day and topical calcipotriol cream. A good response was observed after four weeks of treatment. (Fig. 3). No signs of recurrence were reported within six months of follow-up.

Hailey-Hailey disease (HHD), also known as benign familial pemphigus, is an autosomal dominant condition in which mutations in the ATP2Cl gene result in abnormal intracellular calcium signaling
$\mathrm{Ca}^{+} / \mathrm{Mn}^{+}{ }^{+}$-ATPase isoform 1 (hSPCAl) on the Golgi membrane [1]. Normally this gene plays a part in ensuring that the cells in the outer layer of the skin (the epidermis) stick together. In HHD this adhesion of cells is weakened, resulting in acantholysis in areas of skin prone to friction $[2,3]$. Thereby, heat, sweating, infection and contact irritants can exacerbate skin lesions, for which reasons the disease has a relapsing and remitting course. The rashes are often itchy but painful when scratched [4].The disease usually manifests in adulthood (the 30s and 40s) and is characterized by vesicular lesions, painful erosions, and scaly erythematous plaques that occur at sites of friction such as the armpits and groins. The current case is being reported due to the rare occurrence of the disease on the scalp. Moreover, an extraordinary presentation has rarely been described in the literature. A case of persistent crusted lesion due to HHD was reported on the face of a 25-year-old woman [5]. One more patient

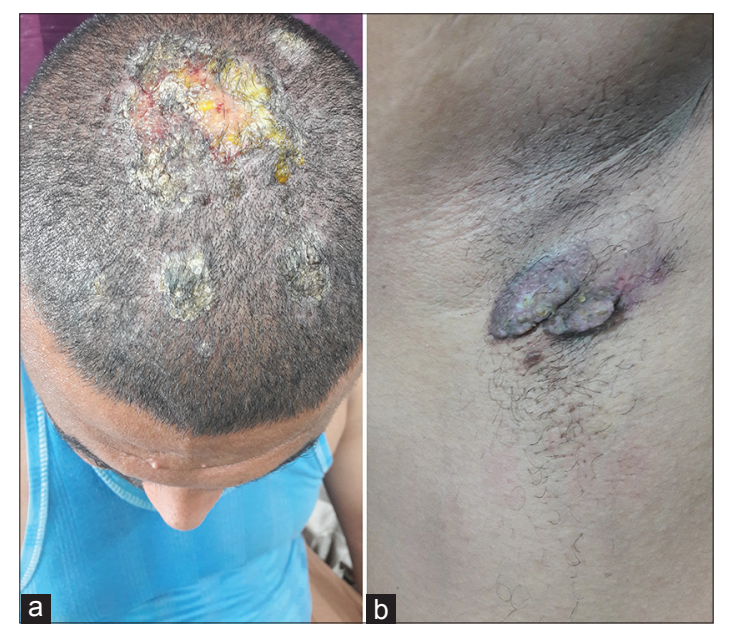

Figure 1: (a and b)A-Four crusted lesions on the scalp, a big one $4 \times 5 \mathrm{~cm}$ near to the vertex, and the other three about $1 \times 2 \mathrm{~cm}$ surrounding the big one. B- A warty plaque measuring $2 \times 3 \mathrm{~cm}$ in the right axilla. 


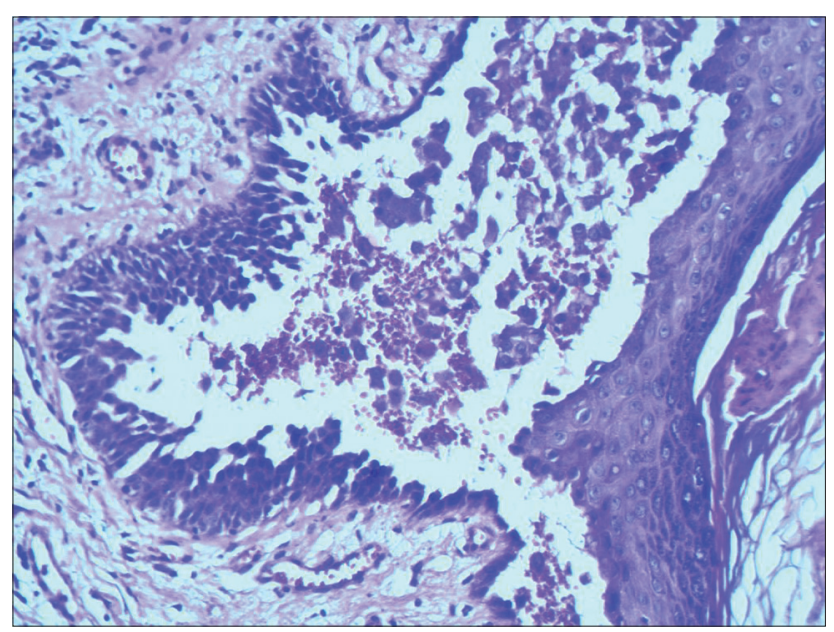

Figure 2: Hematoxylin and eosin (H\&E) 40X, stained skin section showed epidermal cleft and bullous formation containing aggregates of acantholytic cells that arranged in dilapidated brick wall appearance, with papillary protrusion of the basal layer.

was diagnosed as HHD presented with a solitary bulla on the left forearm that had spontaneously ruptured to form an erosion [6]. The clinical differential diagnosis of Hailey-Hailey disease includes intertrigo, candidiasis, inverse psoriasis, tinea cruris, contact dermatitis, and seborrheic dermatitis. In this case, the painful crusted erosion with the history of exacerbation during summer months, suggests the diagnosis of HHD. Histologic differential diagnosis includes other disorders with intraepidermal acantholysis such as pemphigus vulgaris and Darier's disease. The characteristic dilapidated wall appearance with a papillary protrusion of the basal layer are consistent with HHD (Fig. 2). The absence of dyskeratosis like "corp ronds" and "grains" in the suprabasal layer excluded Darier's disease in this case.

Traditional treatments of HHD include topical and systemic antibiotics, topical and oral corticosteroids, dapsone, retinoid, cyclosporin, and methotrexate for patients with recalcitrant disease. For widespread recalcitrant HHD, laser ablation (with $\mathrm{CO} 2$ or Erbium: YAG), radiofrequency, dermabrasion, and botulinum toxin type (BTX -A) have been reported as useful in the literature [7]. We have to consider the possibility of HHD when there are characteristic clinical signs, regardless of the location of the lesion to avoid misdiagnosis. Early diagnosis and treatment can

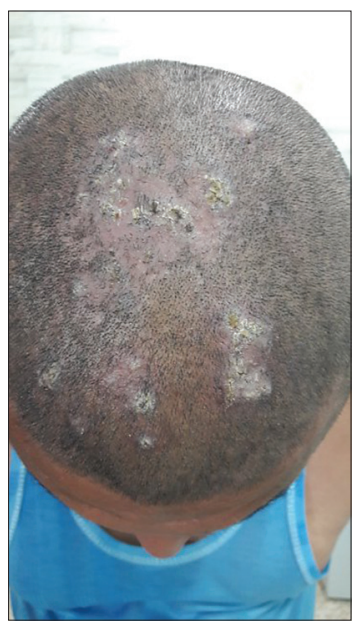

Figure 3: Noticeable response four weeks after treatment

reduce the incidence of complications and improve the patient's quality of life.

\section{REFERENCES}

1. Micaroni M, Giacchetti G, Plebani R, Xiao GG, Federici L. ATP2CI gene mutations in Hailey-Hailey disease and possible roles of SPCA1 isoforms in membarane trafficking. Cell Death Dis. 2016;7:e2259.

2. Chourabi M, H' mida-Ben Brahim D, Bonnard C, Aounallah A, Yu $\mathrm{Ng}$ A, Tohari S, et al. A novel nonsense ATP2CI mutation causes Hailey-Hailey disease in a Tunisian family. Our Dermatol Online 2018:9:110-3.

3. Hassan I, Keen A. Hailey-Hailey disease: a case report. Our Dermatol Online. 2012;3:116-8.

4. Engin B, Kutlubay Z, Celik U, Serdaroglu S, Tuzun Y. HaileyHailey disease: A fold (intertriginous) dermatoses. Clin Dermatol. 2015;33:452-5.

5. Das D, Das A, Gharami R, Bandyopadhyay D. Hailey-Hailey disease: A presentation out of the ordinary. J Turk Acad Dermatol. 2014;8:1484c7.

6. Vasudevan B, Verma R, Badwal S, Neema S, Mitra D, Sethumadhavan T. Hailey -Hailey disease with skin lesions at unusual sites and a good response to acitretin. Indian J Dermatol Venereol Leprol. 2015;81:88-91.

7. Farahnik B, Collin M. Blattner, Micheal B Mortazie, Dirk M. Elston, et al. Interventional Treatment for Hailey -Hailey disease. J Am Acad Dermatol. 2017;76:551-8.

Copyright by Nabeel K. Al Hamzawi. This is an open-access article distributed under the terms of the Creative Commons Attribution License, which permits unrestricted use, distribution, and reproduction in any medium, provided the original author and source are credited.

Source of Support: Nil, Conflict of Interest: None declared. 